\title{
CHOOSING THE RIGHT TYPE AND LOCATION OF THE CITY PUBLIC TRANSPORT STOPS
}

This paper is concerned to tram stop safety in the Czech Republic. Recently some experimental solutions of tram stops (with alternative successes) have been realized in Prague and Brno. These experimental solutions of tram stops, which very often emerged as trial and error, were based on elevated carriageways. Due to the fact that there is lack of qualified information and projection recommendations, I would like to present the selection of information based on real operation experience. The paper has been compiled using results of the grant project No. 103/04/0476 "Proposal of financing traffic attendance methodology", which is being realised thanks to the financial support from the public Grant Agency of the Czech Republic [1].

\section{Introduction}

Passengers' safety in the city public transport is a sense of personal security being felt by passengers. This feeling emerges both from factually installed safety precautions and also from activities ensuring passengers' awareness about these precautions.

It is inevitable to consider traffic safety as a matter of the highest importance. It is also unacceptable to improve other quality criteria, such as velocity, observance of timetable, comfort, etc. to the exclusion of traffic safety. Carriers are obligated to transport passengers safely without jeopardizing their health, lives and properties.

Fear of being a victim of some criminal attack is one of the most significant factor discouraging people from public transport usage. It represents a problem in many cities and results from various type of crime (such as physical attack, robberies in vehicles and stops, vandalism etc.). Those carriers who are able to cope with personal security issues and provide physical help and information enjoy respect among their users.

\section{Location of stops, technical requirements}

Passengers encounter serious obstacles when trying to reach their stop in many cities. Pedestrian access to the stop often comprises complicated crossings through busy roads or unpleasant and dangerous zones.

Location of a public transport stop is more or less a technical matter. However, surveys presented in various EU-projects indicates necessity to consider complex of social, psychological and safety aspects during the process of municipal planning, such as:

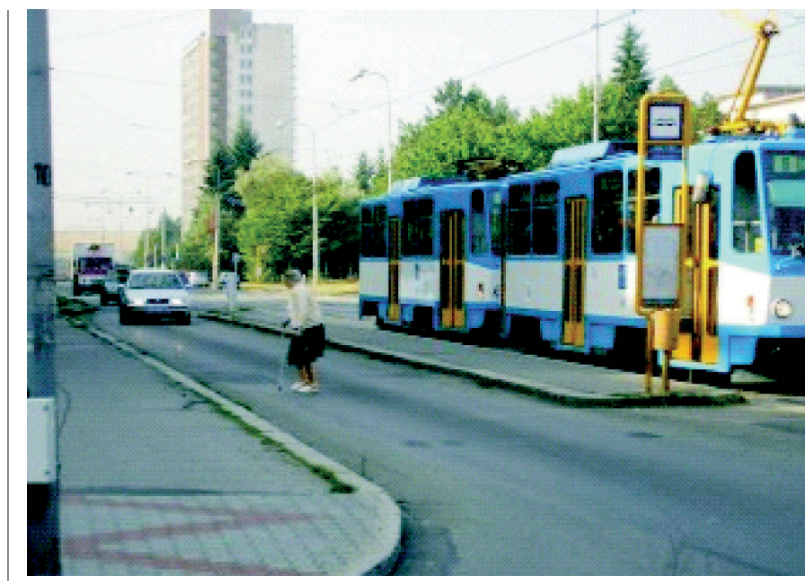

Fig. 1 Access must be free of any dangerous situations and places

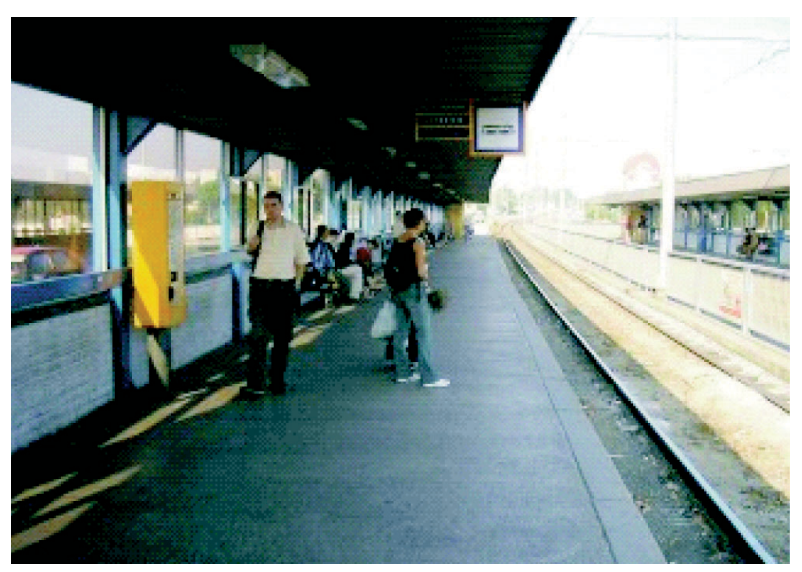

Fig. 2 Clear transparent axes among various components

\footnotetext{
* Ivana Olivková

Institut of Transport, Technical University of Ostrava, tř. 17. listopadu 15, 70833 Ostrava-Poruba, Tel.: 59-732 3122, E-mail: ivana.olivkova@vsb.cz
} 
Interior of a public transport stop should create awareness of security among passengers. This could be achieved by eliminating dark corners and restricting number of pillars to minimum.

Additionally, there should be clear transparent axes between entrances, exits, station halls and platforms in order to enlarge space for orientation and also passengers' sense of security.

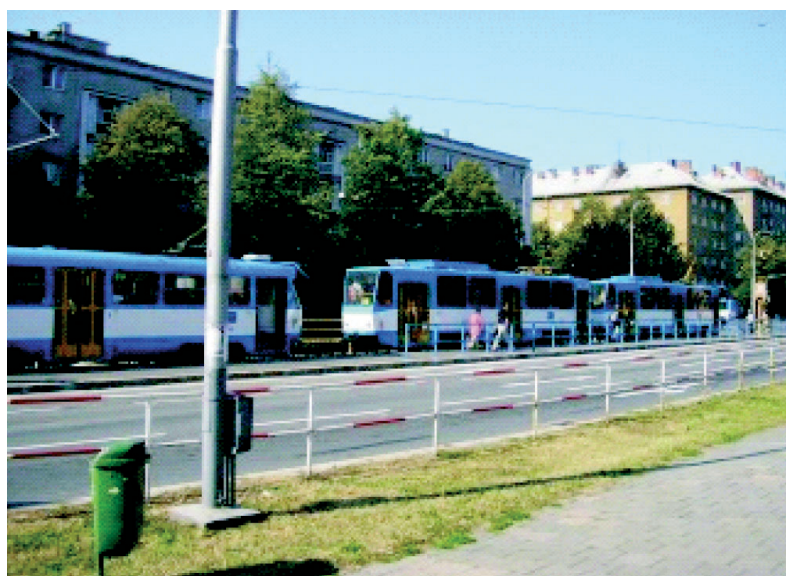

Fig. 3 Satisfactory length of a refuge with regard to trains dimensions

Dimensions of vehicles and trains should be taken into account with regard to space needed for motion and manoeuvring within the stop areas. Design of stops should respect easy cleaning and maintenance.

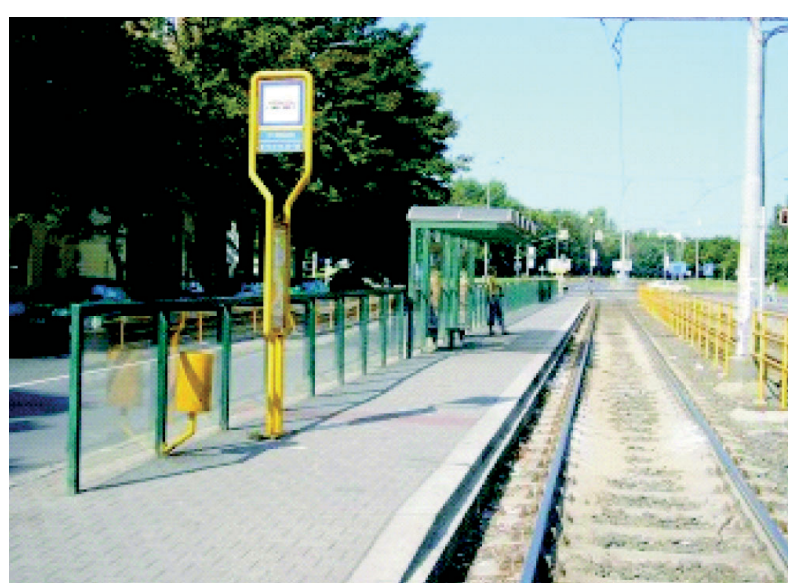

Fig. 4 Daylight usage

Daylight and artificial light should be maximally preferred; for instance installation of glass surfaces in large numbers making public transport travelling more pleasant and increasing sense of comfort and passengers' safety.

Refuges and corridors should be wide enough so as the passengers could feel safely. Travel distance between changes should be as short as possible, with comprehensible marking that gives required information to the passengers and assure them about the right direction of walking.

An easily localizable lifts and escalators should be on grade separation places at the passengers' disposal.

Ticket issue machines should be located near entrances and in vestibules. Harmonized timetables for all means of transport should be also appropriately located.

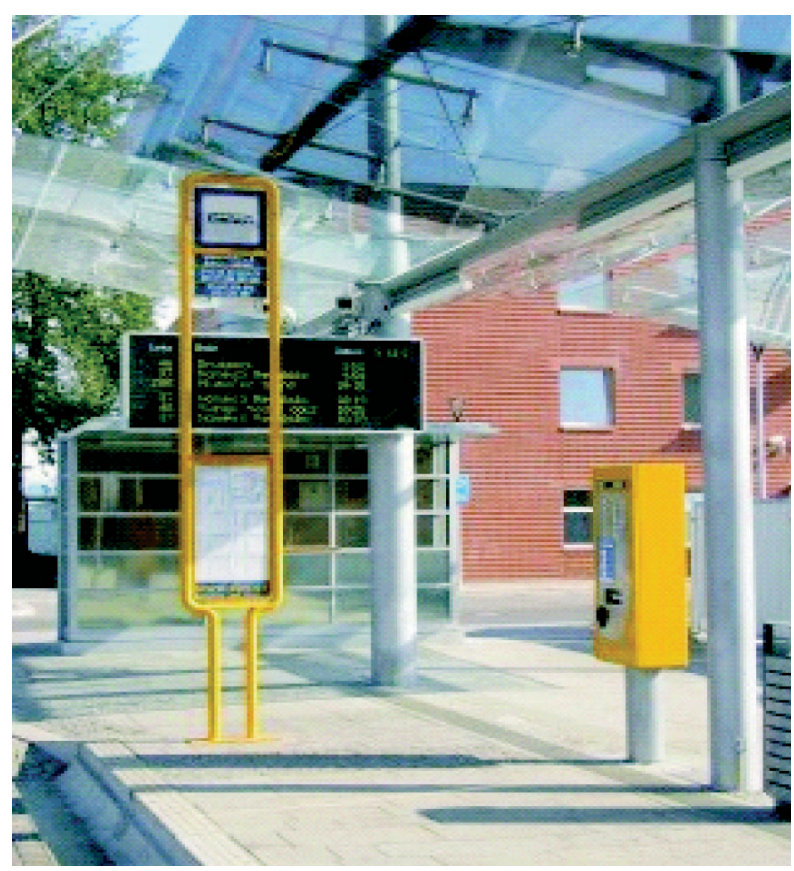

Fig. 5 Refuges and corridors must be designed with regard to carrying capacity and safety

Traffic measures for the disabled are very needful. Moreover, they affect much bigger group of passengers than only disabled. Every measure (such as low-floor vehicles, accessibility of metropolitan railway stops, elevated platforms...) helps also other passengers, especially those with big amount of luggage, children etc.

Intelligent transport system - ITS might be helpful when improving connection among individual transport activities and services, accessibility and safety of stops for passengers. Therefore, it is important to locate stops in a way allowing installation and accessibility of ITS equipment; for instance creating complex informational systems independent on carriers or means of transport. These systems should be multilingual, adapted for demands of disabled people, be located both in stops areas and outside and, lastbut-not-least, combine static (i.e. timetables) and dynamic data about public transport services. 


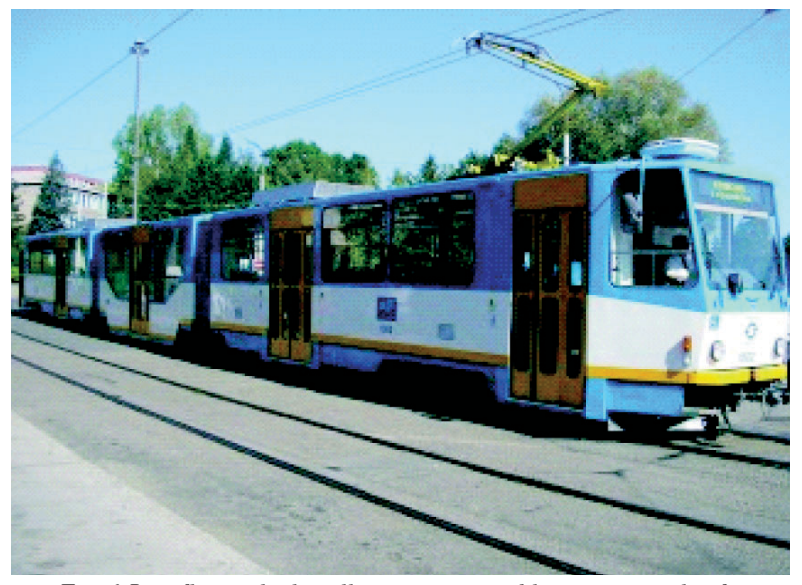

Fig. 6 Low-floor vehicles allow access to public transport also for disabled and elderly people

\section{Choosing the right type of a public transport stop}

There is a compact tramway transportation network with a long tradition and advanced traffic-engineering solution (including tram stops) in city of Vienna, Austria. A new and at the same time very promising type of a tram stop - so-called stop-with-elevatedcarriageway (wrongly also as "passing-traffic-island") - has been designed and tried for the very first time in Vienna, 1992. Efforts for modernizing and improving attractiveness of the tram stops are universal.

Main issues in modernizing public transport stops (actually, public transport preferences) are as follow:

- Passengers exchange development (i.e. more comfortable getting in and out);

- Decreasing difference in elevation between the ground and a vehicle, which is very important for the disabled;

- Withdrawal from stops having exit directly to the carriageways (they are both the least comfortable for passengers and the most difficult problem for the disabled) in favour of stops with either elevated carriageways or bay stops.

During the design stage of a new stop it is essential to respect a lot of evaluating criteria, especially functional requirements (user's requirements) and site available in the street area.

That's why there isn't any general variant preferred or considered as "panacea". Nevertheless, there are some distinctive tendencies towards understanding appropriate order of some stop forms:

- Bay stops - they offer the highest possible protection and passengers may use bigger waiting areas (the carriageway is substituted for pavement within the stop area and motor traffic is led on the track).

- Elevated pavement stops - they are preferred due to their safety merits and low area requirements. While traffic island stops very often mean potential threat to passengers and a lot of accidents of passengers catching trams in the last possible moment are registered, elevated pavement stops accident review are much more favourable.

- Traffic island stops - the most widespread type of stops despite their area requirements. Sometimes it's not possible to find enough space for an island and carriageway axe shift if there are some competing functional requirements in the side areas and at the same time to guarantee side areas wide enough (pavements, cycle tracks and/or residency areas).

As a very important criterion for choosing the right type of a stop form is the way of motor traffic conducting before the stop. In the case of conducting motor traffic predominantly on the track before stop, because there's a parking zone, this should continue even in the stop area. These are the cases of using bay stops.

Building stops with elevated pavement is rather problematical in the case of conducting motor traffic before stops on the tracks. This is due to the fact that as a result of such solution the axe shift of motor traffic carriageway will occur and a lot of drivers would continue to drive on the tracks even in the stop area. They usually do not understand the system of traffic there - see experience from Prague. Additionally, the axe shift of motor traffic also hides significant perils. When used, it should be rather slow in order to allow motor vehicles leaving the tracks in due course.

The stops with elevated pavements were recognised and accepted by the public as effective stop form. Traffic experience with stops having elevated pavements is excellent when keeping some basic conditions. Due to the fact that the stop area is passable even for drivers, they are accepted by them more easily in comparison to the bay stops. Conducting the motor traffic on the tracks, which is the case of the bay stops, often leads to discussion about the waiting of vehicles while a tram is stopping etc.

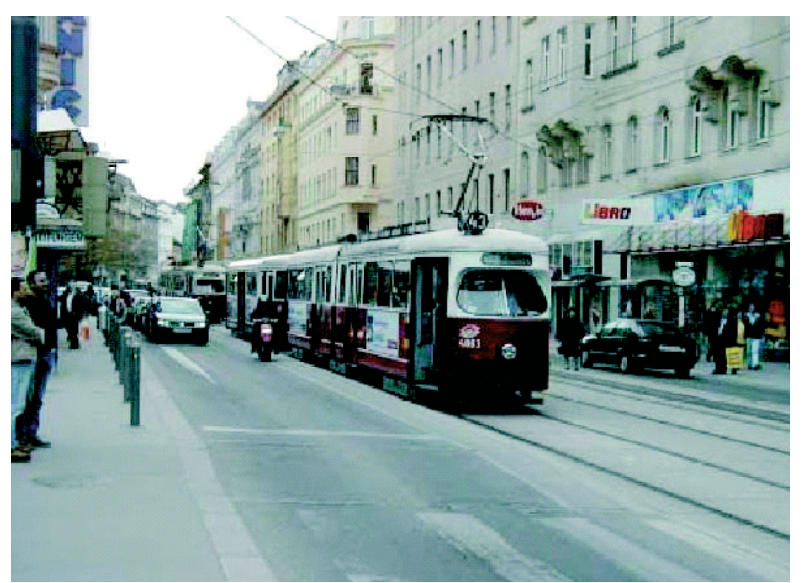

Fig. 7 Tram stop with elevated pavement in the city of Vienna 


\section{Quality standards of public service from the safety point of view}

A quality of carrier service in public transport is being determined by quality standards set for providing public transport.
During the design stage of carrier quality standards in public transport it is essential to set such inviolable qualitative and quantitative limits so as to stay competitive with private car transport. These data might be used as referential for evaluating current conditions of public transport system. The intention of the quality standards

CRITERION: TECHNICAL CAPABILITY OF THE EQUIPMENT

\begin{tabular}{|c|c|c|}
\hline & PUBLIC STOP & PUBLIC TRANSPORT VEHICLE \\
\hline $\begin{array}{c}\text { DEFINITION } \\
\text { OF A STANDARD }\end{array}$ & $\begin{array}{l}\text { Distance post safely fixed, having good technical } \\
\text { conditions, with a good surface finish. } \\
\text { Reflex panel (or plastic "beacon") safely attached } \\
\text { and in good technical conditions. } \\
\text { Platform in a good condition, flat surface, with } \\
\text { gradient and functional draining. } \\
\text { Shelter safely anchored, in a good technical condition, } \\
\text { undamaged. } \\
\text { Street furniture - bench, rubbish bin in a good } \\
\text { technical condition, properly fixed. }\end{array}$ & $\begin{array}{l}\text { Technical condition of a vehicle must be adequate, } \\
\text { ground surface without any projections and failures, } \\
\text { seats and handles must be properly attached. } \\
\text { Device for opening and closing doors, ventilating } \\
\text { system, heating system, radio equipment must } \\
\text { work properly. } \\
\text { Information cavettos, device for attaching the course } \\
\text { number and for attaching orientation directional } \\
\text { boards must be in good technical conditions. } \\
\text { No scratched, splashy or doodled glasses are allowed. }\end{array}$ \\
\hline $\begin{array}{l}\text { UNACCEPTABLE } \\
\text { LIMITS }\end{array}$ & $\begin{array}{l}\text { Distance post impends to fall, corroded, heavily } \\
\text { damaged surface finish. } \\
\text { Reflex panel (or plastic "beacon") is missing, badly } \\
\text { attached, heavily damaged. } \\
\text { Platform has uneven surface, dangerous for passengers, } \\
\text { deep puddles occur. } \\
\text { Shelter is incorrectly fixed and damaged. } \\
\text { Street furniture - bench, rubbish bin damaged, } \\
\text { incorrectly fixed. }\end{array}$ & $\begin{array}{l}\text { Technical devices are clearly out of order. } \\
\text { Damage of windows or bodyworks by vandals is noti } \\
\text { ceable. }\end{array}$ \\
\hline DEMAND LEVEL & $95 \%$ of conditions must be out of unacceptable limits. & $95 \%$ of conditions must be out of unacceptable limits. \\
\hline $\begin{array}{l}\text { MEASUREMENT } \\
\text { METHODS }\end{array}$ & $\begin{array}{l}\text { Visual check. This is carried out by } 1 \text { worker from the } \\
\text { transport operation check group with } 1 \text { worker from } \\
\text { the operation group. Each stop is being inspected } 2 x \\
\text { per year, in the case of backbone exposed stops } 12 x \\
\text { per year. }\end{array}$ & $\begin{array}{l}\text { Visual check. This is carried out by workers from } \\
\text { the measurement transport operation group. The } \\
\text { inspection comprises of } 100 \text { samples per month, } \\
\text { reliability performance inspection of fleet acoustics } \\
\text { devices is carried out } 1 \mathrm{x} \text { per year. }\end{array}$ \\
\hline
\end{tabular}

\section{CRITERION: PASSENGER SAFETY}

\begin{tabular}{|c|l|l|}
\hline \multicolumn{1}{|c|}{ DEFINITION } & VISIBLE MONITORING & STAFF/ POLICE ATTENDANCE \\
\hline OF A STANDARD & $\begin{array}{l}\text { Newly built terminals must be monitored. The } \\
\text { CCD-cameras are in operation and must be situated } \\
\text { in a way that all stations/stops are clearly visible. } \\
\text { Transmission of a signal to the transport operation } \\
\text { centre is ensured. The CCD-cameras are in operation } \\
24 / 7 \text { year-round (workdays, weekends and bank } \\
\text { holidays included). }\end{array}$ & $\begin{array}{l}\text { Security service/Police must be present in newly } \\
\text { built terminals. They should ensure security in the } \\
\text { terminals by regular checks every 2 hours. }\end{array}$ \\
\hline UNACCEPTABLE LIMITS & $\begin{array}{l}\text { The CCD-cameras are inconveniently situated } \\
\text { (stations/stops are not clearly visible). There's no } \\
\text { transmission of a signal to the transport operation } \\
\text { centre. Monitoring is off. }\end{array}$ & $\begin{array}{l}\text { Security service/Police is not present in terminal. } \\
\text { Security is not ensured. }\end{array}$ \\
\hline DEMAND LEVEL & 95\% of conditions must be out of unacceptable limits. & 95\% of conditions must be out of unacceptable limits. \\
\hline MEASUREMENT & Random check 3x per year. & Random check 3x per year. \\
\hline METHODS & & \\
\hline
\end{tabular}


is presentation and service-monitoring reasons of carriers. The main objective is to create conditions for ensuring an eminent share of transport services by improving their quality.

Carrier quality service from the safety point of view refers to the following criteria:

- Technical capability of the equipment (stops, public transport vehicles);

- Private safety (visible monitoring, staff attendance, first-aid station marking).

Standards for each criterion of the quality of service have been set. They comprise:

- Definition of a standard (being characterized by the service provided or - in the case of technical equipment - determines its operation capability);

- Unacceptable limit (being characterized by absolutely unacceptable situations considered as service failure, which bring about immediate reactions for restoring the service;

- Demand level (being determined by the share of service provided in the demanded and suitable quality to the total number of monitored samples);
- Measurement method (presents instruction for choosing appropriate measurement methods)

The following table presents quality standards of individual criteria with regard to the object.

\section{Conclusion}

The paper deals with passengers' security issues in the means of public transport and stops in municipalities, where all participants of road transport might be jeopardised. An objection is to create conditions for increasing public transport share during division of transport labour by improving quality in safety matters. Offering quality in passenger transport is a basis for decreasing volume of cars in cities. As for the quantity point of view, passenger transport is being ensured rather easily, but user's demands rising especially in quality area in terms of safety matters.

\section{References}

[1] SUROVEC, P., OLIVKOVÁ, I., KŘIVDA, V.: Proposal of financing traffic attendance methodology. VŠB TU Ostrava, Institut dopravy, 2004. Grant Project No.103/04/0476 realized under financial support of the Grant Agency of the Czech Republic.

[2] ANGENENDT, W., BRÄUER, D., KLÖCKNER, D.: Mittellage-Haltestellen mit Fahrbahnanhebung, Berichte der Bundesanstalt für Straßenwesen, Bergisch Gladbach, 2002.

[3] Quality of interchanges, Conquest Research for London Transport Marketing (1997).

[4] RUNKEL, M: Stations in public transport, UITP Revue, Vol 43, Nº 5. (pp.32-36) (1994).

[5] Public transport in stations: location, functional design and management and operations of public transport stations. UITP (1993). Brussels. 